\title{
EXPLORING TEACHERS' ATTITUDE AND KNOWLEDGE IN TEACHING STATISTICS BASED ON RASCH MEASUREMENT MODEL
}

\author{
Nur Faishah Abdul Halid, Zamalia Mahmud, Shamsiah Sapri and Balkish Mohd Osman \\ Centre of Statistical and Decision Science Studies \\ Faculty of Computer and Mathematical Sciences \\ Universiti Teknologi MARA, Malaysia \\ zamalia@tmsk.uitm.edu.my
}

\begin{abstract}
Teachers with a positive attitude towards statistics and good statistical knowledge are important in preparing students to learn statistics effectively. This study explores 49 mathematics teachers' attitude and knowledge in teaching statistics at selected secondary schools in Selangor. Fortynine mathematics teachers from the urban and rural secondary schools were surveyed using the attitude toward statistics questionnaire and statistics assessment form. Data collected was subjected to an analysis based on the Rasch measurement model. Wright map shows that slightly over 50\% of the teachers with positive attitude towards statistics perceived well in their knowledge in teaching certain statistical concepts. Differential item functioning indicates no significance difference in the attitude of teachers between rural and urban schools. Teachers with less than 10 years experience have better knowledge in graph representation and measures of central tendency while teachers with more than 10 years have better knowledge in measures of dispersion and probability.
\end{abstract}

\section{INTRODUCTION}

National Council of Teachers of Mathematics (NCTM, 2019) highlighted that students, teachers, administrators and employers have increasingly recognised statistics as an important scientific field of study. In the teaching of statistics at the secondary school level in Malaysia, the main emphasis is on how to describe the data rather than making inferences about the data. Lessons on data handling is becoming one of the integral components in the Malaysian school's mathematics curriculum with the emphasis on statistical thinking at the lower secondary level. However, in the Malaysian schools mathematics curriculum, statistical topics are embedded in the mathematics syllabus where majority of the teachers are trained to teach mathematics rather than statistics. Therefore, it is expected that mathematics teachers have little knowledge and understanding about teaching statistics. This situation has raised concern to the statistics educators at the tertiary level as to whether mathematics teachers are showing positive attitude towards teaching statistics and whether they have sufficient knowledge to teach statistics (Batanero, Burril, \& Reading, 2011). While it is important for the teachers to have adequate knowledge in statistics, the concern is also on the amount of training received by the teachers prior to teaching statistics to the students (Batanero \& Diaz, 2010).

Hence, this study is conducted to examine the mathematics teachers' attitude towards teaching statistics and whether they have adequate knowledge to teach statistics at the secondary school level. Other measures include looking at the differences in their attitude and statistical knowledge based on school locations and length of teaching experience.

\section{METHOD}

A survey method was used to gather information about teachers' attitude and knowledge in teaching statistics. The study employed a one-stage cluster sampling in selecting the schools and mathematics teachers at the secondary schools in the Selangor. Forty-nine teachers (23 rural; 26 urban) with high (27) and low teaching experience (22) have been identified as the sample of the study. Survey responses were gathered from the questionnaires developed based on a focus group interview with teachers and analysed based on Rasch measurement model using Winsteps 3.90.2 software (Linacre, 
2002; 2011). Among the Rasch measurement tools used in the analysis are person and item reliability index, separation index, mean square outfit and infit, wright map and differential item functioning (DIF) (Bond \& Fox, 2007).

In order to capture the attitude responses, a 5-point Likert scale ranging from strongly disagree, disagree, neutral, agree and strongly agree are suitably used to represent the polytomous Rasch model. Responses to items may reflect one or more underlying, ability or attitude. Davis (2004) stated that polytomous items yield a higher model level of information across larger span of scales and tend to result in smaller item pools. The general probability of person $n$ scoring $x$ on items $i$ given $\beta_{n}$ and $\delta_{i}$ at different threshold level $\tau_{\mathrm{k}}$ is shown below (Bond \& Fox, 2007).

$$
P_{n i k}\left\{X=1 \mid \beta_{n}, \delta_{i}, \tau_{k}\right\}=\frac{\exp \left(\beta_{n}-\delta_{i}-\tau_{k}\right)}{1+\exp \left(\beta_{n}-\delta_{i}-\tau_{k}\right)}
$$

where

$P_{n i k}\left\{X=1 \mid \beta_{n}, \delta_{i}, \tau_{k}\right\}=$ The probability of person $n$ choosing "strongly disagree" over "strongly agree"

$\beta_{n}=$ estimated person ability on any item $i$

$\delta_{i}=$ difficulty of the entire item

$\tau_{k}=$ difficulty of the $k^{\text {th }}$ threshold

\section{RESULTS AND DISCUSSION}

Table 1. Summary statistics for attitude towards teaching statistics

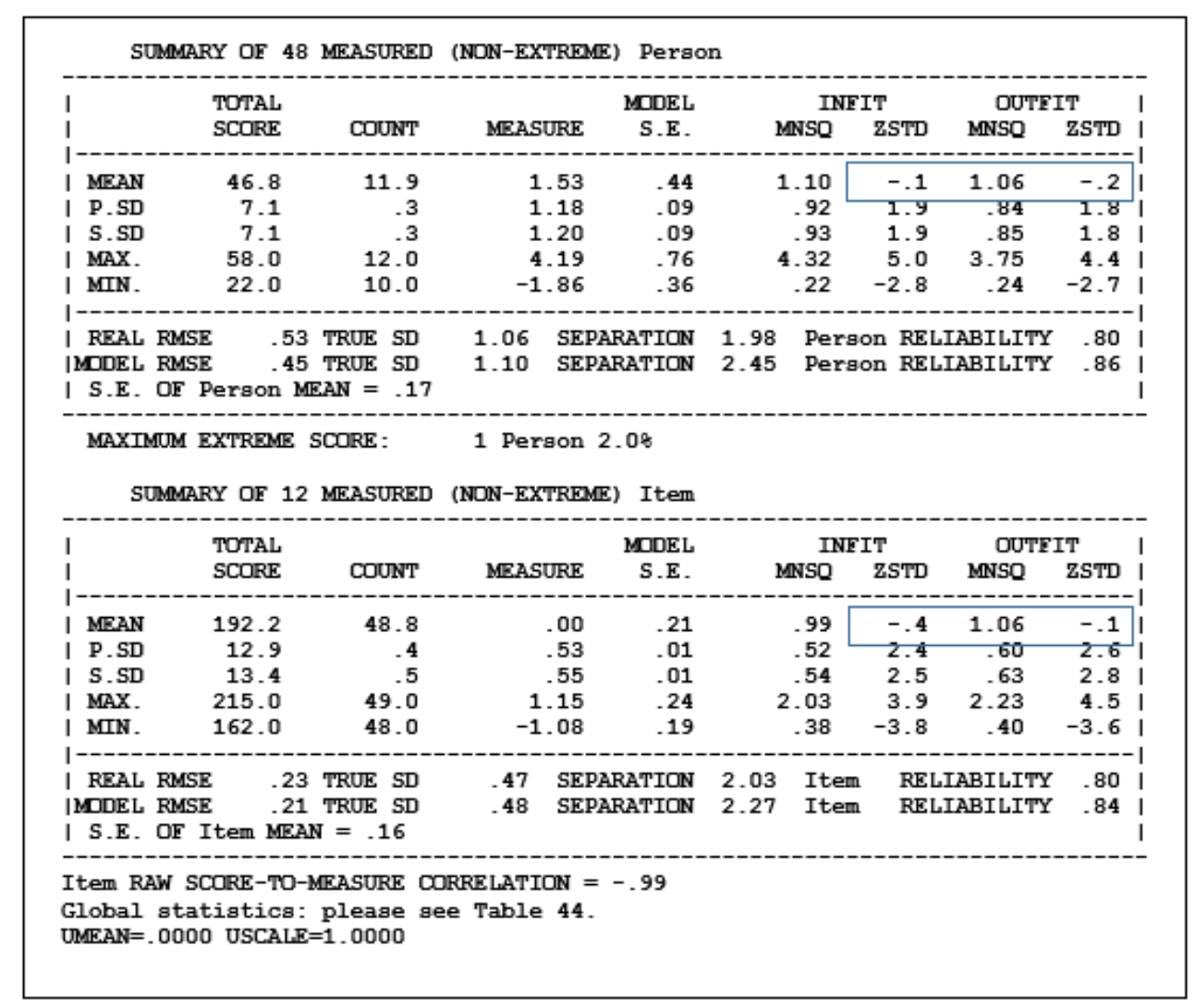


Table 1 shows a high reliability index for person and item measure both at 0.80 , indicating that the items are in line with the person responses and are replicable for measuring the same traits (Mahmud, 2011). The mean square infit and outfit for person and item measures are all close to 1.00 indicating an acceptable fit. The person mean logit at 1.53 suggest that most of the attitude items are easy to agree with. The separation index for person was 1.98 signified a maximum of two levels for person ability along a continuum. The item separation index of 2.03 for attitude indicates that the maximum level of item endorsement is 2 , which is either agreed or disagreed.

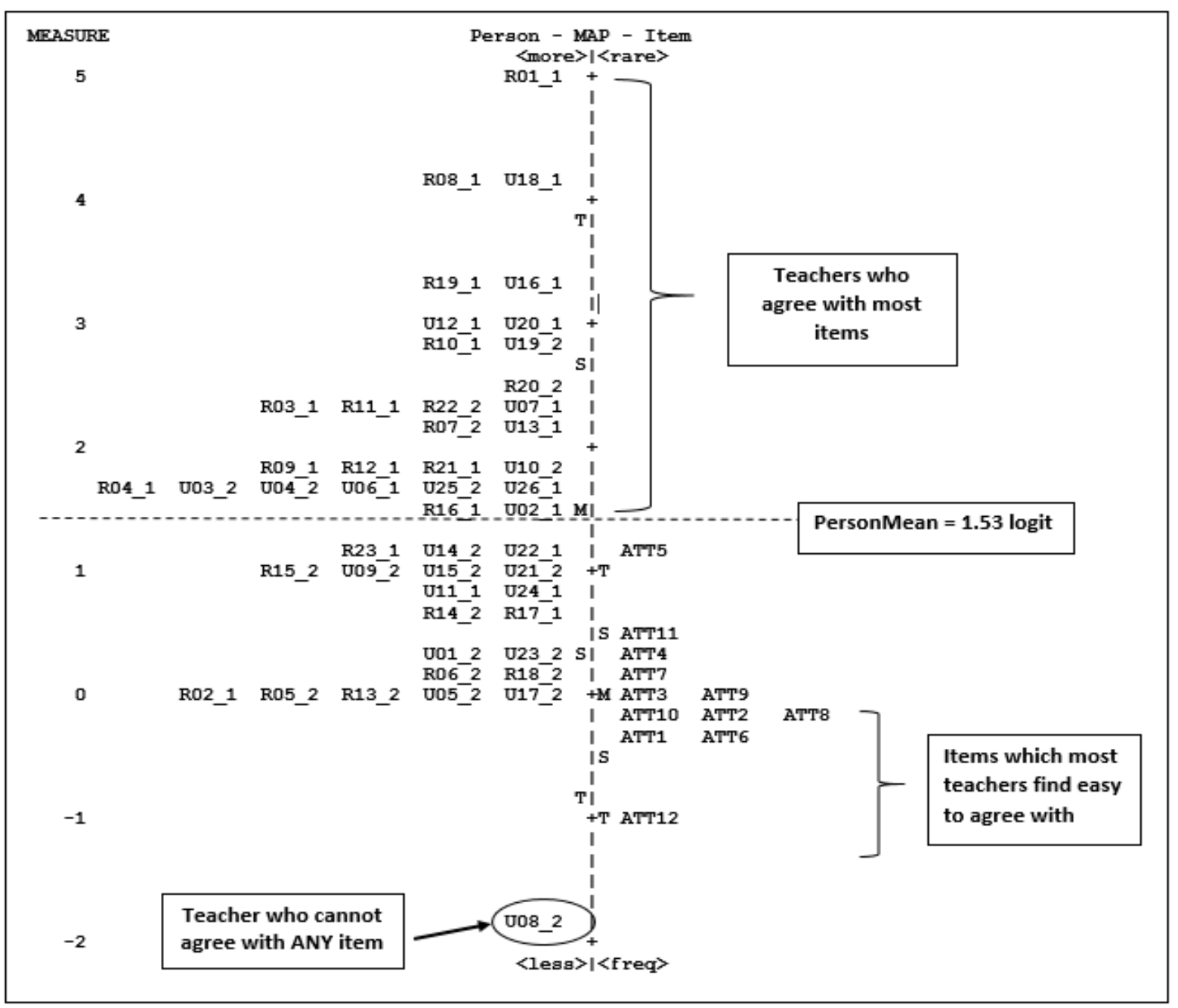

Figure 1. Wright map of teachers' attitude towards teaching statistics

Figure 1 shows that the attitude items are equally located below and above the item mean logit (0.00 logit). About 57\% of the teachers (28/49) tend to agree with most of the attitude items indicating a positive attitude while 41\% (20/49) were neutral. Only one teacher (U08_2) from the urban school was found to be slightly negative about teaching statistics based on its lowest person logit value at -1.8 . Most teachers find ATT5 item (I find it easy to explain probability concepts to my students) was easy to agree with, while item ATT12 (If I could eliminate part of syllabus, it would not be statistics) was difficult to agree with by a teacher from the urban school. 


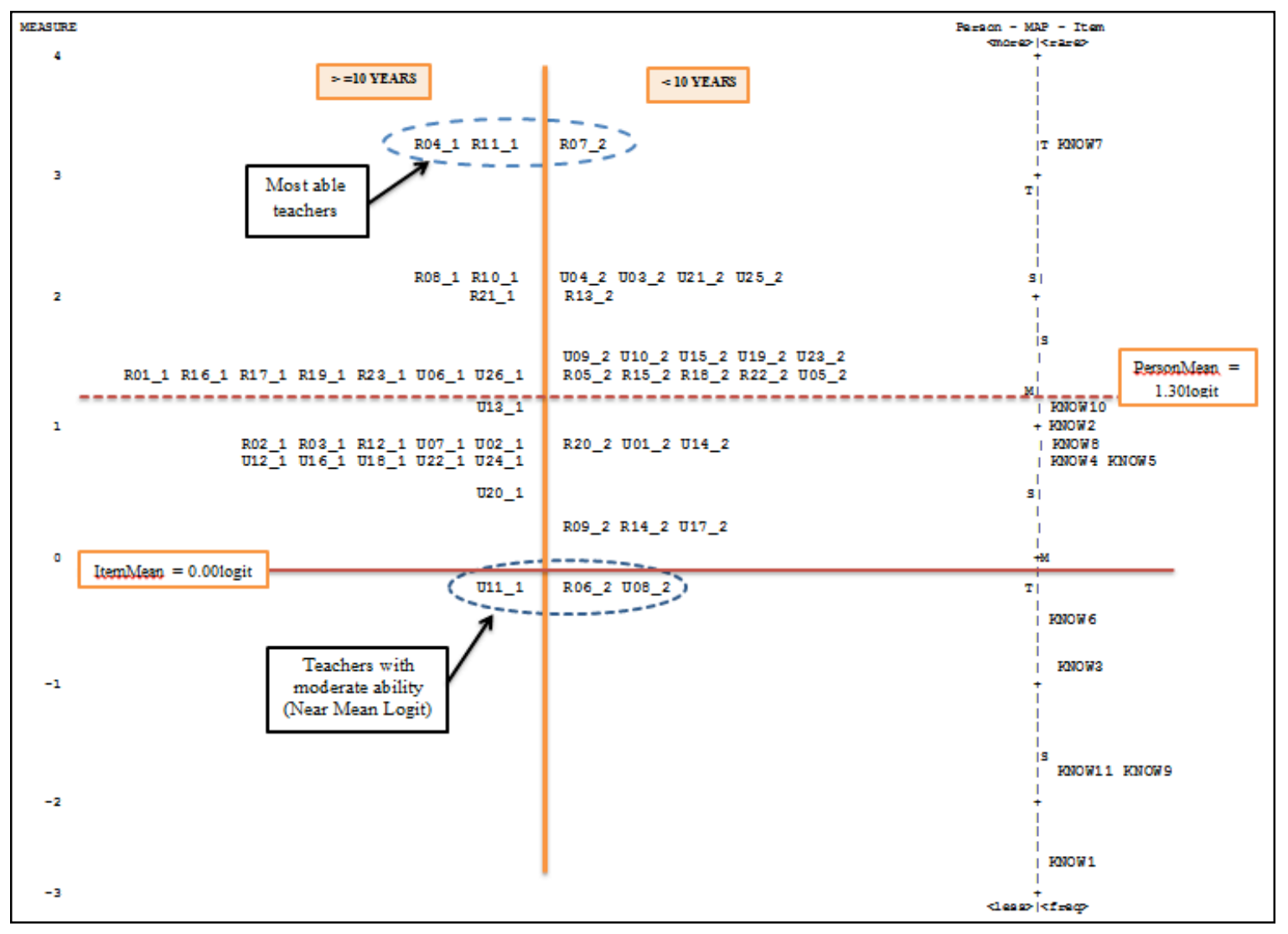

Figure 2. Wright map of teachers' statistical knowledge

Figure 2 shows that three teachers from the rural schools (R04_1, R11_1, R07_2) have equal and highest ability each at 3.25 logit (located at the top of the map). On the other hand, there were three teachers (U11_1, R06_2 and U08_2) with lowest ability at -0.26 logit, located at the bottom of the map. Teachers who have taught mathematics for more than 10 years have a better understanding on most statistical topics compared to those with less than 10 years experience. The most difficult item to endorse is KNOW7 (Each column of histogram represents a group defined by a categorical variable), located at the top of the map while the easiest item KNOW1 (Graphs are used to present and interpret data in a meaningful) is located at the bottom of the map. In addition, the map also show that teachers with more than 10 years experience in teaching mathematics score higher than those with less than 10 years experience. The spread of items located along the logit scale indicates that the statistics knowledge include both difficult and easy items.

DIF is used to investigate the difference in attitude items between teachers in the rural and urban schools, and between lengths of teaching experience. According to Wyse and Mapuranga (2009), DIF occurs when teachers from different school locations with similar attitude exhibit different probabilities of endorsing an item. For the difference to be significant, it has to be at least 0.5 logit (Linacre, 2002).

Results of DIF analysis for 12 attitude items shows no significant difference between rural and urban teachers since all DIF contrasts are less than 0.5 logit and the value of t-test is less than \pm 2.0 logit. In spite of this, Figure 3 shows that item ATT5 (I find it easy to explain probability concepts to my students) and ATT6 (I do not have trouble teaching statistics because of how I think) appeared to be more difficult for teachers from urban schools to agree with compared to rural schools. Item ATT7 (I feel that statistics should be required early in school level) and item ATT8 (Teaching statistics requires a great deal of skills and discipline) appeared to be more difficult for teachers from the rural school to agree with compared to urban schools. 


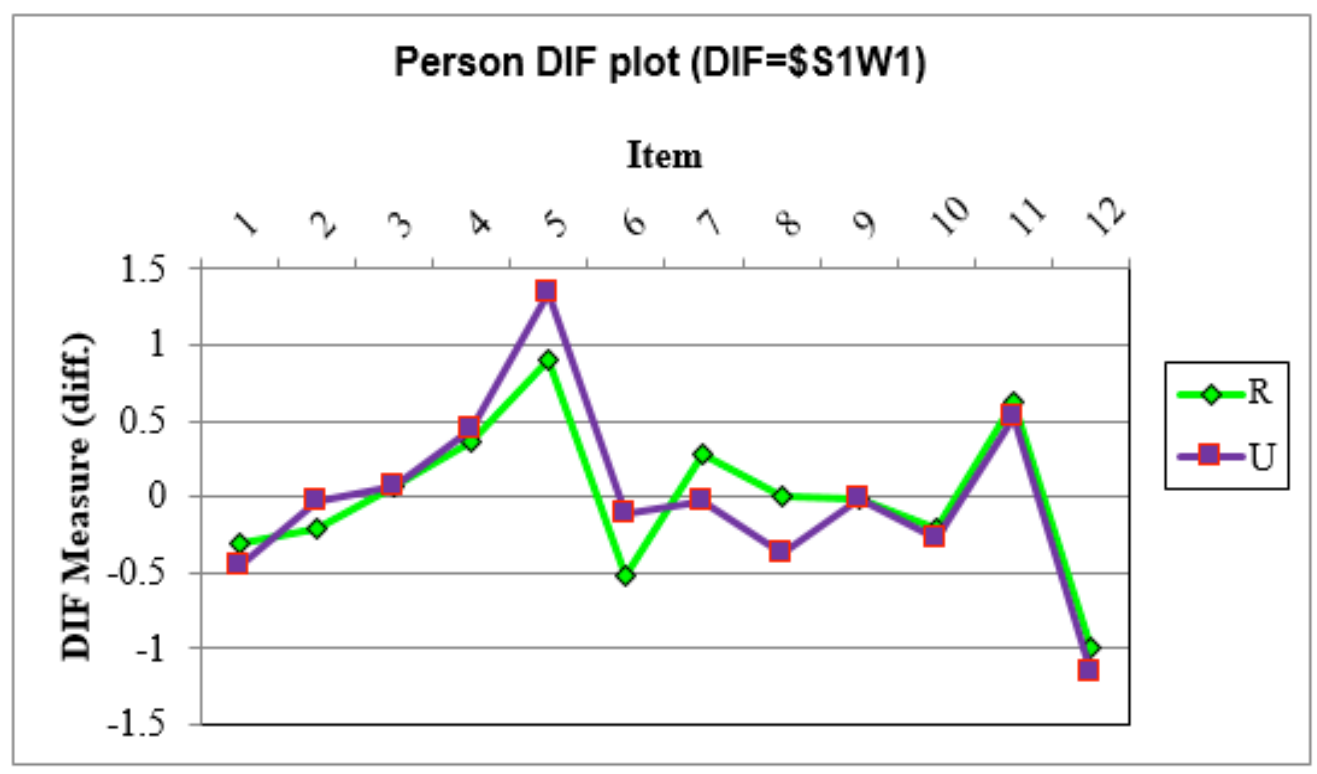

Figure 3. DIF for attitude towards statistics between school locations

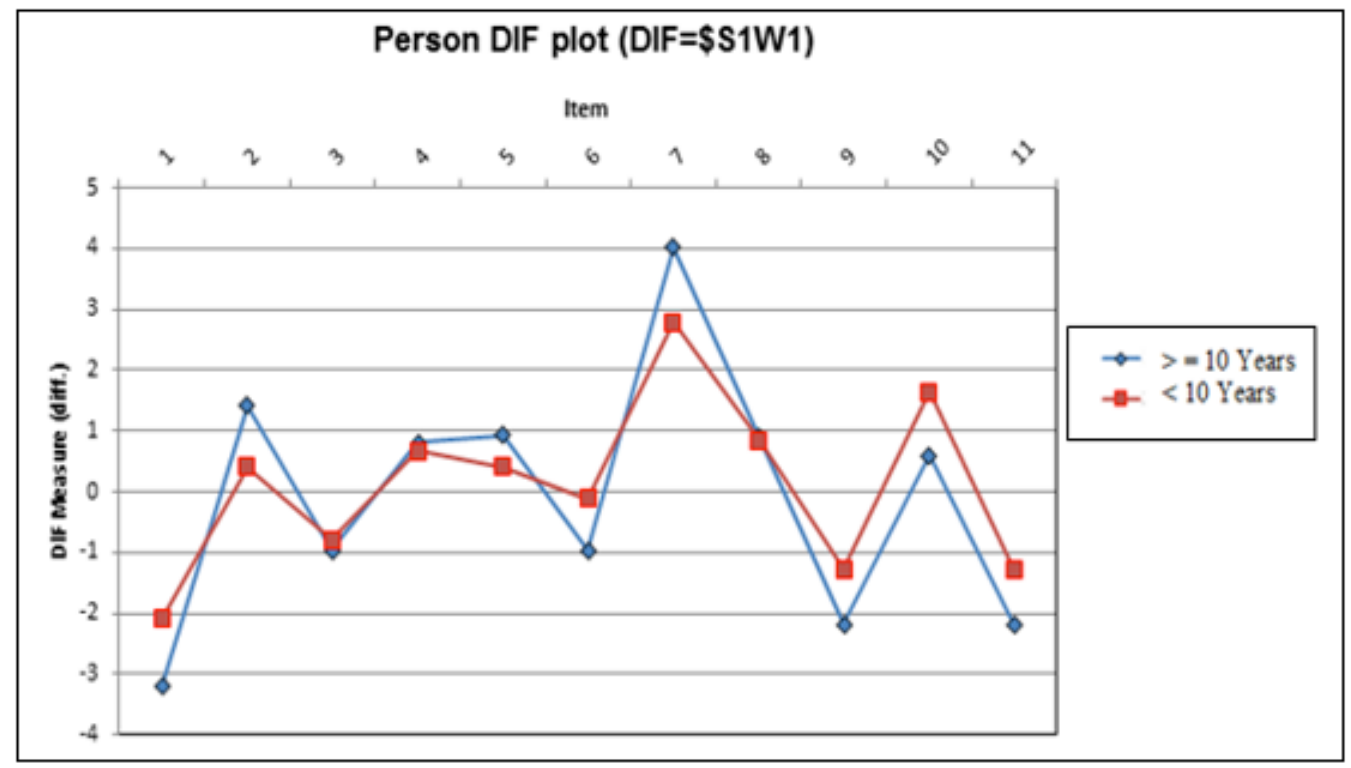

Figure 4. DIF for statistical knowledge between teaching experiences

Figure 4 shows that items KNOW2 (Statistics is a process of collecting and presenting data only), KNOW 5 (Stem-and-leaf plot is used for presenting quantitative data in a graphical format) and KNOW7 (each column of histogram represents a group defined by a categorical variable) seem to be more difficult to endorse by teachers with more than 10 years of teaching experience compared to less than 10 years.

\section{CONCLUSION}

Reasoning with data requires knowledge and understanding of statistical concepts. Statistics teaching can be more effective if teachers have the right statistical knowledge and attitude to teach 
statistics. Teachers with statistical misconceptions and negative attitude might miss opportunities to help students achieve a deeper understanding of core statistical concepts. This study has illustrated the use of Rasch measurement model as an approach in appraising teachers' attitude and knowledge about statistics. It shows mathematics teachers need to be positive in their attitude towards statistics and require more training to teach statistics effectively. While there was no significant difference in the teachers' attitude based on location of schools, a significant difference was observed based on their teaching experience. In spite of these results, this study is limited to mathematics teachers under study and does not represent teachers at other schools. In order to ensure that mathematics teachers are able to teach statistics well, the Ministry of Higher Education Malaysia should provide more on-going statistics courses and training workshops for them. This study could be expanded to other samples and set as a benchmark to other related studies.

\section{REFERENCES}

Batanero, C., Burill, G., \& Reading, C. (Eds.) (2011). Teaching statistics in school mathematics challenges for teaching and teacher education. A Joint ICMI/IASE Study: The 18th ICMI Study (Vol 14). Springer Science \& Business Media.

Batanero, C., \& Diaz, C. (2010). Training teachers to teach statistics: What can we learn from research? Statistique et enseignement, 1(1), 5-20.

Bond, T. G. \& Fox, C. M. (2007). Applying the Rasch model: Fundamental measurement in the human sciences $\left(2^{\text {nd }}\right.$ ed). Mahwah, NJ: Lawrence Erlbaum Associates Publishers.

Davis, L. L. (2004). Strategies for controlling item exposure in computerized adaptive testing with the generalized partial credit model. Applied Psychological Measurement, 28(3), 165185.

Linacre, J.M. (2011). Practical Rasch Measurement. Retrieved from www.winsteps.com

Linacre, J.M. (2002). Understanding Rasch Measurement: Optimal Rating Scale Category Effectiveness. Journal of Applied Measurement, 3(1), 85-106.

Mahmud, Z. (2011). Rasch Probabilistic Model as a Diagnostic Tool to Gauge Student's Attitude Towards Learning Statistics. In Proceedings of the $8^{\text {th }}$ WSEAS International Conference on Engineering Education, $2^{\text {nd }}$ International Conference on Education and Educational Technologies.

National Council of Teachers of Mathematics, NCTM (2019). Preparing Pre-K-12 Teachers of Statistics. A Joint Position Statement of the American Statistical Association (ASA) and the National Council of Teachers of Mathematics (NCTM).

Wyse, A. E., \& Mapuranga, R. (2009). Differential item functioning analysis using Rasch item information functions. International Journal of Testing, 9(4), 333-357. 